\title{
ENFRENTAMIENTO DE LA RESPIRACIÓN DISFUNCIONAL EN NIÑOS Y ADOLESCENTES
}

\author{
Comentario del artículo: "Getting to grips with disfunctional breathing" \\ Paediatr Respir Rev 2015; 16: 53-61
}

\section{Nicki Barker MSc ${ }^{1}$, Mark Lloyd Everard MD²}

1. Department of Respiratory Medicine, Sheffield Children's Hospital, Western Bank, Sheffield,UK

2. School of Paediatrics and Child Health, University of Western Australia, Princess Margaret Hospital for Children, Western Australia

El diagnóstico diferencial de la dificultad respiratoria asociada al ejercicio en un niño o adolescente es muy amplio (1-3). Muchos clínicos asumen que el paciente es asmático, diagnóstico que es válido solo en cierta proporción de pacientes. Sin embargo pocos consideran que puede haber una causa alternativa, o que el niño claramente tiene asma y además alguna comorbilidad, y por este motivo no responde al tratamiento. Entre los diagnósticos alternativos los más comunes son las limitaciones impuestas por la obesidad, la aversión de un individuo para realizar ejercicio, la intolerancia al esfuerzo respiratorio asociado al ejercicio o una falla para reconocer que cuando están experimentando síntomas es debido a que están en el límite de su capacidad cardiovascular y por lo tanto la disnea es fisiológica. Esta última entidad se observa principalmente en los niños o adolescentes que ansían participar en deporte (o cuyos padres están deseosos que su hijo participe) e incluye tanto a individuos entrenados como aquellos sin acondicionamiento físico. Entre las causas raras se encuentran condiciones tales como la taquicardia supra-ventricular inducida por el ejercicio o el shunt intra-pulmonar del síndrome hepatopulmonar.

La disfunción de cuerdas vocales (DCV) generalmente se incluye en la lista de diagnósticos diferenciales en el grupo de adolescentes con episodios de dificultad respiratoria con el ejercicio $(4,5)$, sin embargo esta condición parece ser solo un componente de la amplia gama de respiración disfuncional $(\mathrm{RD})$ y aquellos con DCV representan una minoría dentro de este grupo $(1,6-8)$.
Esta respiración disfuncional parece ser relativamente común, pero insuficientemente reconocida (9-12). Esta condición no es tan frecuente en edad escolar, su prevalencia parece aumentar a través de la adolescencia y aunque los datos son limitados entre los adultos estaría presente en 8 a $10 \%$ de la población general y en un $30 \%$ de la población asmática, confundiéndose con el "asma de difícil manejo ". La identificación es importante ya que su tratamiento es muy efectivo y no requiere el uso de medicamentos. La fisioterapia basada en entrenamiento respiratorio mejora dramáticamente los puntajes clínicos y la calidad de vida $(1,13,14)$.

La respiración disfuncional se puede definir como una "alteración en los patrones biomecánicos normales de respiración que resultan en síntomas intermitentes o crónicos". En la Figura 1 se describen los tipos de respiración disfuncional.

En la mayoría de los casos la causa es funcional, como respuesta habitual a situaciones de stress 0 ansiedad agudos 0 crónicos. Sin embargo es importante conocer la existencia de causas estructurales que pueden inducir síntomas similares con el ejercicio incluyendo la laringomalacia inducida por ejercicio. Esta puede confundirse con una disfunción paroxística de las cuerdas vocales. Otra alteración es la respiración disfuncional torácica caracterizada por excesivo uso de los músculos intercostales y accesorios, con escasa contribución del diafragma. Este patrón se caracteriza por episodios de ansiedad, como el inducido por ver una película de terror o en alguna situación de peligro, y puede volverse crónico o ser desencadenado por situaciones de stress tales como deporte competitivo 0 actuación musical.

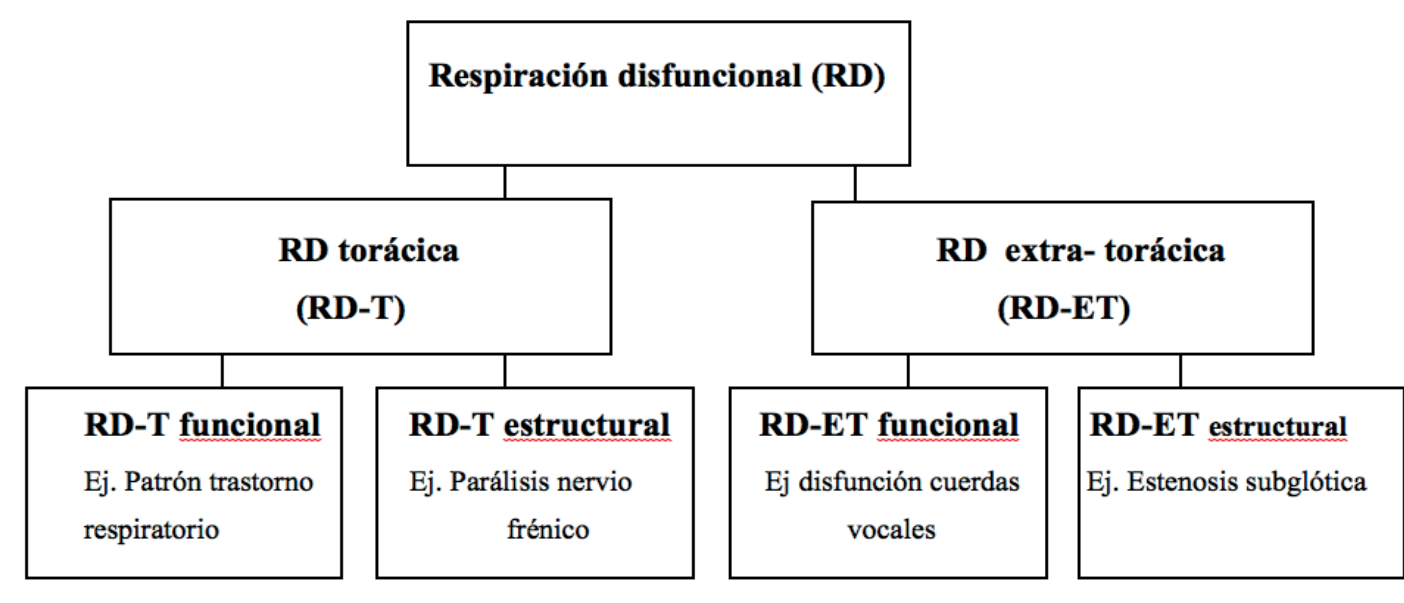

Figura 1. Visión general de la respiración disfuncional 
Muchos casos de DVC se sobreponen sobre una disfunción respiratoria torácica. Es fundamental reconocer esta asociación ya que el tratamiento de ambas implica las mismas técnicas de rehabilitación respiratoria, agregando algunas más específicas para la DCV.

Como se señaló anteriormente la condición puede ocurrir en conjunto 0 sin asma, 0 con otras patologías respiratorias. En una revisión retrospectiva de 34 pacientes que acudieron a nuestra clínica de respiración disfuncional 21 tenían asma, y habían sido derivados por asma de difícil manejo. Los 13 restantes no tenían asma, y estaban con terapia inhalatoria. Una minoría presentaba además DCV.

Esta condición ha recibido atención por más de 150 años. Se ha denominado de diversas formas: síndrome de De Costa, corazón del soldado, y síndrome de hiperventilación. Este último ha sido objeto de mucha discusión y finalmente se dejó de usar esta nomenclatura ya que generalmente no se podía demostrar el nivel arterial bajo de C02 y la prueba de hiperventilación carecía de especificidad (14). Desafortunadamente esto condujo a dejar de tomar en cuenta esta condición que tenía gran impacto en la calidad de vida y más allá de solo síntomas respiratorios

Se reconoce la respiración disfuncional como una comorbilidad importante o diagnóstico alternativo de asma en las guías británicas, GINA y guías australianas (15-17). Las guías de la British Thoracic Society refieren que los pacientes presentan "respiración anormal, con sensación de falta de aire, a menudo descrito como "hambre de aire", sensación de incapacidad para inhalar hasta el final, pudiendo estar acompañados de otros síntomas, por ejemplo, opresión en el pecho, ansiedad, mareos 0 parestesias. Estos síntomas colectivamente caracterizan un síndrome, comúnmente conocido como síndrome de hiperventilación o respiración disfuncional. Muchos asmáticos hiperventilan crónicamente y pueden tratarse, por lo tanto, de la misma forma ".

Lamentablemente no se cuenta con pruebas sencillas que identifiquen la condición, aunque la prueba de esfuerzo cardiopulmonar puede proporcionar información concluyente. En la mayoría de los casos el diagnóstico se basa en la historia clínica, con sobre o sub-diagnóstico. Los fisioterapeutas logran caracterizar los patrones de respiración y son muy eficientes para resolver los problemas a través de ejercicios de rehabilitación y relajación.

Los aspectos de la historia que puede proporcionar pistas sobre su presencia incluyen: 1. La situación durante la cual aparecen los síntomas: reposo o poco después de iniciar una actividad ( la broncoconstricción debido al ejercicio por lo general toma alrededor de 5 minutos en manifestarse) pero nunca cuando el sujeto está dormido, 2. Una "respuesta parcial" a un broncodilatador; 3. Recurrencia rápida al reiniciar la actividad y la sensación de "hambre de aire", como se ha descrito anteriormente 4. El sujeto toma una respiración completa y siente que todavía puede inhalar más aire. 5. Para aquellos con componente laringeo pueden describir la sensación de estrechamiento u opresión en la garganta o dificultad para conseguir aire a través de la vía aérea superior. 6. Si hay un ruido asociado serán sibilancias? Será estridor? 7. Se debe tener en cuenta que muchos sujetos son manejadores y a menudo no manifiestan signos de ansiedad.
Como en gran parte de la medicina respiratoria, el reconocimiento de patrones es muy importante al sospechar el diagnóstico, y trabajando en estrecha colaboración con fisioterapeuta respiratorio con un interés particular en esta área puede tener un enorme impacto en la vida de los individuos afectados.

\section{REFERENCIAS}

1. Barker N, Everard ML. Getting to grips with 'dysfunctional breathing'. Paediatr Respir Rev. 2015; 16: 53-61

2. Abu-Hasan M, Tannous B, Weinberger M. Exercise-induced dyspnea in children and adolescents: if not asthma then what? Ann Allergy, Asthma \& Immunol. 2005;94:366-71

3. Weinberger M, Abu-Hasan M. Perceptions and pathophysiology of dyspnea and exercise intolerance. Pediatr Clin North Ame. 2009;56:33-48

4. Noyes BE, Kemp JS. Vocal cord dysfunction in children. Paediatr Respir Rev 2007; 8:155-63

5. Maturo S, Hill C, Bunting G, Baliff C, Ramakrishna J, Scirica C, et al. Pediatric paradoxical vocal-fold motion: presentation and natural history. Pediatr 2011; 128: e1443-e9

6. Courtney R. The functions of breathing and its dysfunctions and their relationship to breathing therapy. Int $\mathrm{J}$ of Osteopathic Med 2009; 12: 78-85

7. Peper E, Tibbetts V. Effortless diaphragmatic breathing. Phys Ther 1994; 6:67-71

8. Clifton Smith T, Rowley J. Breathing pattern disorders and physiotherapy. Phys Ther Rev 2011; 16: 75-86

9. Thomas M, McKinley RK, Freeman E, Foy C. Prevalence of dysfunctional breathing in patients treated for asthma in primary care: cross sectional survey. BMJ 2001; 322: 1098-100

10. Thomas M, McKinley RK, Freeman E, Foy C, Price D. The prevalence of dysfunctional breathing in adults in the community with and without asthma. Prim Care Respir J.2005; 14: 78-82 11. Keeley D, Osman L. Dysfunctional breathing and asthma. It is important to tell the difference. BMJ. 2001; 322: 1075-6

12. Lum LC. Hyperventilation: The tip and the iceberg. J Psychosom Res. 1975; 19: 375-83

13. Holloway EA, West RJ. Integrated breathing and relaxation training (the Papworth method) for adults with asthma in primary care: a randomised controlled trial. Thorax 2007 ; 62: 1039-42 14. Gardner WN. Hyperventilation. Am Journal Respir Crit Care Med 2004;170:105-6

15. http://www.asthmahandbook.org.au/diagnosis/adults/ alternative-diagnoses

16. Bott J, Blumenthal S, Buxton M, Ellum S, Falconer C, Garrod R et al. British Thoracic Society Physiotherapy Guideline Development Group. Guidelines for the physiotherapy management of the adult, medical, spontaneously breathing patient. Thorax 2009; 64 Suppl 1:i1-51

17. http://www.ginasthma.org/local/uploads/files/GINA Report 2015.pdf p 9 -40 


\title{
MICROBIOMA RESPIRATORIO E INTERACCIONES MICROBIANAS Comentario del artículo: 'Recurrent lower respiratory tract infections' - going around in circles, respiratory medicine style
}

\author{
Mark Lloyd Everard \\ Paediatric Respiratory Unit, Sheffield Children's Hospital, Western Bank, Sheffield, UK
}

Convencionalmente se considera la vía aérea inferior estéril. Varios mecanismos de protección evitan el paso de bacterias hacia ella 0 las elimina si alcanzan el pulmón. Estos incluyen estructuras como la barrera mecánica de la laringe, clearance mucociliar, la tos, péptidos antibacterianos, macrófagos residentes y otras células fagocíticas.

Los rápidos avances tecnológicos en la secuenciación genética y biología computacional han puesto en evidencia un vasto mundo de microorganismos no cultivables que colonizan hábitats tan diferentes como estratos de roca ubicados varios kilómetros por debajo de la tierra hasta superficies internas y externas de organismos multicelulares. Se estima que las bacterias que viven en un individuo pesan 1 a $2 \mathrm{~kg}$, y superan en número a nuestras propias células por 100 veces. Ahora se reconoce que muchos de estos organismos juegan un papel importante asegurando nuestra salud a través de la interacción con nuestro sistema inmunológico, la producción de nutrientes esenciales, eliminando posibles toxinas y patógenos potenciales.

Este trabajo sugiere que los pulmones tienen su propio microbioma residente, que consiste en virus, bacterias y otros microorganismos (1-3). Se sabe poco acerca de la microbiota de la vía aérea baja en comparación con la que se encuentra en boca, intestino o piel, en gran parte debido a dificultad para obtener muestras no contaminadas. Aún existe controversia acerca de la existencia de un microbioma pulmonar "normal". Además de las dificultades para obtener muestras no contaminadas, Ios reactivos utilizados en su procesamiento contienen ADN bacteriano (4). Tampoco se sabe mucho sobre el rol potencial del microbioma residente en la modulación del sistema inmune dentro de las vías respiratorias.

No obstante, tenemos información en cuanto a la importancia de las interacciones entre los organismos y su huésped. Aunque muchos han tratado de establecer un vínculo entre la infección viral del tracto respiratorio bajo y el desarrollo posterior de asma, pareciera que lo determinante es la respuesta individual del huésped $(5,6)$. No hay duda que los virus inducen exacerbaciones de asma durante las cuales se pierde la respuesta a beta- agonistas (7), pero estos agentes actúan como factor gatillante más que como causa de la enfermedad. Es probable que esta pérdida de respuesta beta-agonista en una exacerbación se debe al ARN viral que induce una respuesta inflamatoria la cual a su vez vuelve hiposensible los betareceptores del músculo liso (8). En los lactantes y niños en edad preescolar las infecciones virales del tracto respiratorio inferior son comunes debido a los niveles inadecuados de anticuerpos neutralizantes. Estas infecciones se caracterizan por una intensa inflamación neutrofílica con edema de la mucosa y abundantes secreciones en la vía aérea $(9,10)$. Por eso no es sorprendente que la obstrucción ocurre en la vía aérea baja. En los lactantes muy pequeños en los cuales la obstrucción resulta en el cierre de la vía aérea pequeña en la espiración aparece la "bronquiolitis aguda", con abundantes crepitaciones (10). El mismo proceso inflamatorio en un un lactante mayor o niño pequeño no llega al cierre de la vía aérea (y por eso no hay crepitaciones), sino que se produce limitación al flujo aéreo asociado a la auscultación de sibilancias (una sibilancia simplemente implica limitación al flujo aéreo). De ahí que un niño en edad preescolar con bronquitis sibilante (es decir tienen una bronquitis viral y se producen sibilancias debido a la limitación al flujo aéreo resultante de secreción y edema de la mucosa) parece idéntica a la 'asmática' en la cual la broncoconstricción es el principal componente en la generación de la limitación del flujo y sibilancias resultantes (10). Es difícil distinguir entre ambos, pero es importante hacerlo ya que los asmáticos se benefician con la terapia con corticoides mientras que los niños con bronquitis sibilante tienen poca 0 nula respuesta.

Mientras que el virus sincicial respiratorio fue considerado durante mucho tiempo como el organismo que más probablemente inducía asma atópica, los estudios indican que es el huésped más que el virus quien determina las futuras manifestaciones de la enfermedad. Más recientemente, se ha propuesto que el rinovirus humanos y la colonización temprana con patógenos bacterianos tales como Haemophilus influenza no tipificable y Streptococcus pneumonia serían la causa. Sin embargo, parece que la presencia de los agentes patógenos y los problemas que causan serían marcadores de características del huésped y no indica que el patógeno en sí está contribuyendo al desarrollo de la atopia o enfermedad $(5,6)$. Aún se desconoce si los componentes del microbioma respiratorio juegan algún rol en el desarrollo del asma y atopia, ya sea positivo o negativo. Muchos trabajos realizados con el microbioma intestinal han sugerido mecanismos mediante los cuales ese vínculo podría establecerse (11) pero como con todos los nuevos campos es muy probable que muchas de las hipótesis actuales no se logren confirmar.

Es muy probable que los virus tengan un rol en el desarrollo de la bronquitis bacteriana mediante el daño al epitelio con pérdida de cilios exponiendo al epitelio a la formación 
de biofilm (12). Las infecciones virales desencadenarían exacerbaciones en los sujetos con bronquitis prolongada, bronquiectasias y EPOC probablemente a través de la liberación de organismos del biofilm (13). La importancia de la interacción viral - bacterias se conoció por los resultados de un estudio realizado en niños en edad preescolar, quienes asistían a una guardería. En ellos la magnitud de la descarga nasal durante una infección viral se correlacionó directamente con la densidad de Haemophilus no tipificable y / o Estreptococo pneumoniae en la nasofaringe, indicando que este jugaba un rol importante en la severidad del resfrío, presumiblemente conduciendo la respuesta inflamatoria (14). Durante mucho tiempo se ha reconocido que las neumonías bacterianas a menudo siguen infecciones virales y hay vínculos temporales entre el peak de infecciones respiratorias virales (como VRS e influenza) y luego un peak posterior de neumonía (15). La capacidad de los organismos para influir en la salud humana y en este caso en la vía aérea está impulsando la investigación en el posible uso de tratamientos 'probióticos' para la colonización por Estafilococo aureus multiresistente, la prevención de la otitis media y condiciones asociadas, uso de fagos bacterianos para tratar los biofilm en pacientes con fibrosis quística y agentes capaces de impedir o interrumpir la formación de biofilm.

El campo de estudio de la interacción huésped/ agente infeccioso y agente/agente infeccioso constituye la veta más emocionante de la investigación respiratoria en los próximos años y tiene el potencial para generar nuevos enfoques para la salud y a la vez las enfermedades crónicas.

\section{REFERENCIAS}

1. Beck JM, Young VB, Huffnagle GB. The microbiome of the lung. Transl Res. 2012; 160: 258-66

2. Bassis CM, Erb-Downward JR, Dickson RP, Freeman CM, Schmidt TM, Young VB, Beck JM, Curtis JL, Huffnagle GB. Analysis of the upper respiratory tract microbiotas as the source of the lung and gastric microbiotas in healthy individuals. MBio. 2015; 6: e00037

3. Everard ML. The unified airway - a bug's eye view. Paediatr Respir Rev. 2012; 13:133-4

4. Salter SJ, Cox MJ, Turek EM, Calus ST, Cookson WO, Moffatt MF, Turner P, Parkhill J, Loman NJ, Walker AW. Reagent and laboratory contamination can critically impact sequence-based microbiome analyses. BMC Biol. 2014; 12: 87

5. Elphick HE, Ritson S, Rigby AS, Everard ML. Phenotype of acute respiratory syncytial virus induced lower respiratory tract illness in infancy and subsequent morbidity. Acta Paediatr. 2007; 96: 307-9.

6. Bønnelykke K, Vissing NH, Sevelsted A, Johnston SL, Bisgaard $H$. Association between respiratory infections in early life and later asthma is independent of virus type. J Allergy Clin Immunol. 2015. pii: S0091-6749(15)00325-5

7. Reddel H, Ware S, Marks G, Salome C, Jenkins C, Woolcock A. Differences between asthma exacerbations and poor asthma control. Lancet. 1999; 353: 364-9

8. Van Ly D, Faiz A, Jenkins C, Crossett B, Black JL, McParland B, Burgess JK, Oliver BG. Characterising the mechanism of airway smooth muscle $\beta 2$ adrenoceptor desensitization by rhinovirus infected bronchial epithelial cells. PLoS One. 2013; 8: e56058. doi: 10.1371/journal.pone.0056058

9. Everard ML, Swarbrick A, Wrightham M, McIntyre J, Dunkley C, James PD, Sewell HF, Milner AD. Analysis of cells obtained by bronchial lavage of infants with respiratory syncytial virus infection. Arch Dis Child. 1994 ; 71: 428-32

10. Everard ML. Acute bronchiolitis and croup. Pediatr Clin North Am. 2009; 56: 119-33

11. Thorburn AN, McKenzie Cl, Shen $\mathrm{S}$ et al. Evidence that asthma is a developmental origin disease influenced by maternal diet and bacterial metabolites. Nat Commun. 2015;6:7320 12. Craven V, Everard ML. Protracted bacterial bronchitis: reinventing an old disease. Arch Dis Child. 2013; 98: 72-6

13. Chattoraj SS, Ganesan S, Jones AM, Helm JM, Comstock AT, Bright-Thomas R, LiPuma JJ, Hershenson MB, Sajjan US. Rhinovirus infection liberates planktonic bacteria from biofilm and increases chemokine responses in cystic fibrosis airway epithelial cells. Thorax. 2011; 66: 333-9

14. Rodrigues F, Foster D, Nicoli E, Troter C, Vipond B, Muir P et al. Relationships between rhinitis symptoms, respiratory viral infections and nasopharyngeal colonization with Streptococcus pneumoniae, Haemophilus influenzae and Staphylococcus aureus in children attending daycare. Pediatr Infect Dis J. 2013; 32: 227-32

15. Madhi SA, Klugman KP; Vaccine Trialist Group. A role for Streptococcus pneumoniae in virus-associated pneumonia. Nat Med. 2004; 10: 811-3 